\title{
Trichosanthin induced apoptosis in HL-60 cells via mitochondrial and endoplasmic reticulum stress signaling pathways
}

\author{
Jie $\mathrm{Li}^{\text {a }}$, Xuechun Xia ${ }^{\text {a }}$, Yibao Ke ${ }^{\text {a }}$, Huiling Nie ${ }^{\text {a,* }}$, Mark A. Smith ${ }^{\text {b }}$, Xiongwei Zhu ${ }^{\text {b,* }}$ \\ a Institute of Biochemistry and Cell Biology, Shanghai Institutes for Biological Sciences, Chinese Academy of Science, \\ Graduate School of the Chinese Academy of Sciences, 320 Yue-Yang Road, Shanghai 200031, P.R. China \\ ${ }^{\mathrm{b}}$ Department of Pathology, Case Western Reserve University, Cleveland, OH 44106, USA
}

Received 29 November 2006; received in revised form 13 April 2007; accepted 22 April 2007

Available online 3 May 2007

\begin{abstract}
Trichosanthin (TCS), a traditional Chinese medicine, exerts antitumor activities by inducing apoptosis in many different tumor cell lines. However, the mechanisms remain obscure. The present study focused on various caspase pathways that may be involved in TCS-induced apoptosis in leukemia HL-60 cells. Key caspases in both intrinsic and extrinsic pathways including caspase-8, -9 and -3 were activated upon TCS treatment. Additionally, TCS treatment induced upregulation of BiP and CHOP and also activated caspase-4, which for the first time strongly supported the involvement of endoplasmic reticulum stress pathway in TCS-induced apoptosis. Interestingly, although caspase- 8 was activated, Fas/Fas ligand pathway was not involved as evidenced by a lack of induction of Fas or Fas ligand and a lack of inhibitory effect of anti-Fas blocking antibody on TCS-induced apoptosis. Instead, caspase- 8 was activated in a caspase- 9 and -4 dependent manner. The involvement of mitochondria was demonstrated by the reduction of mitochondrial membrane potential and release of cytochrome $c$ and Smac besides the activation of caspase-9. Further investigation confirmed that caspase- 3 was the major executioner caspase downstream to caspase- $9,-4$ and -8 . Taken together, our results suggested that TCS-induced apoptosis in HL-60 cells was mainly mediated by mitochondrial and ER stress signaling pathways via caspase- 3 .
\end{abstract}

(C) 2007 Elsevier B.V. All rights reserved.

Keywords: Trichosanthin; Apoptosis; Caspase; Mitochondria; Endoplasmic reticulum stress

\section{Introduction}

Trichosanthin (TCS), a type I ribosome-inactivating protein (RIP), exerts antitumor activities by inducing apoptosis in several cell lines, including human choriocarcinoma, HeLa and murine melanoma cells [1-4]. Although many of these studies demonstrated the cleavage/activation of caspase 3 , the mole-

Abbreviations: TCS, trichosanthin; RIP, ribosome-inactivating protein; ER, endoplasmic reticulum; DEVD-CHO, $N$-acetyl-Asp-Glu-Val-Asp aldehyde; z-VAD-FMK, benzyloxycarbonyl-Val-Ala-Asp-fluoromethylketone; z-IETD-FMK，Z-Ile-Glu-Thr-Asp-fluoromethylketone; z-LEHD-FMK, z-Leu-Glu-(O-ME)-His-Asp(O-Me) fluoromethyl ketone; cyto c, cytochrome $c$; z-YVAD-FMK, Z-Tyr-Val-Ala-Asp-(OMe)-fluoromethylketone; COX IV, Cytochrome C Oxidase subunit IV, Ac, acetate

* Corresponding authors. H. Nie is to be contacted at fax: +86 2154921384 .

E-mail addresses: hlnie@sibs.ac.cn (H. Nie), Xiongwei.zhu@case.edu (X. Zhu). cular mechanisms and apoptotic pathways upstream to caspase3 activation remain elusive.

Apoptosis is a genetically regulated process which has an essential role in chemotherapy-induced tumor-cell killing $[5,6]$. Central to this suicidal program is a cascade of caspases with caspase- 3 being one of the key executioners which in turn are cleaved/activated by various initiator caspases. It is well accepted that in mammalian cells, there are two major pathways involved in apoptosis: the mitochondria-initiated intrinsic pathway and the death receptor-triggered extrinsic pathway [7-9]. For the former, proapoptotic signals provoke the release of cytochrome $c$ from the mitochondrial intermembrane space into the cytosol, which forms a complex with Apaf-1 and dATP known as apoptosome and triggers caspase9 activation. The activation of caspase- 9 leads to the activation of the executioner caspases, such as caspase-3, -6, -7 , which triggers a series of apoptotic events and eventually cell death $[7,10,11]$. The extrinsic pathway begins with a 
death receptor, such as Fas. When Fas ligand binds to the Fas death receptor, the adaptor molecule is recruited to the receptors, which allows the binding and proteolysis of procaspase- 8 to activate the caspase- 8 . The activated caspase- 8 then processes the effector caspases, including caspase-3, -6 and -7 , and leading to cell death $[8,10,12]$. Crosstalk exists between the two apoptotic pathways [13-16]. Emerging evidence supports the endoplasmic reticulum (ER) to be another center of regulation for cell death with its own initiator caspase, specifically, caspase- 4 in human and caspase- 12 in mice $[9,17,18]$. The ER plays an important role in maintenance of intracellular calcium homeostasis, protein synthesis, posttranslational modifications, and proper folding of proteins as well as their sorting and trafficking. Many stimuli, including alterations in calcium homeostasis and accumulation of unfolded proteins in the ER, can cause stress $[9,19]$ and prolonged ER stress will lead to apoptosis via caspase-4 dependent pathway. Crosstalk with the two well-characterized pathways also exists since ER stress can also activate caspase9 by releasing cytochrome $c$ from mitochondria to cytosol and activate caspase- $8[19,20]$.

In the present study we focused on mechanisms involved in TCS-induced caspase-3 cleavage/activation and apoptosis. We first demonstrated that TCS induced caspase-dependent apoptosis in HL-60 cells. Interestingly, although both initiator caspases- 8 and -9 are activated, it appears that the Fas/Fas ligand pathway is not involved in TCS-induced apoptosis while caspase- 8 is activated via caspase-9-dependent pathway. The involvement of a mitochondrial pathway is also confirmed by the release of cytochrome $c$ and Smac into cytosol upon TCS-treatment. Most importantly, our data suggest the involvement of the ER stress signaling pathway in TCSinduced apoptosis as demonstrated by the activation of caspase-4 and upregulation of ER-stress related proteins upon TCS-treatment.

\section{Materials and methods}

\subsection{Materials}

TCS was the product of Shanghai Jinshan Medical Factory. Anti-caspase-8, $-9,-3$ and Smac antibodies were purchased from Cell Signaling Technology, Inc. (MA, USA). Caspase-4 antibody was the product of Biomol (PA, USA). Antiactin polyclonal antibody, propidium iodide (PI), DiOC6(3) and Hoechst 33258 were obtained from Sigma(MO, USA). z-IETD-FMK, z-LEHD-FMK, z-YVAD-FMK, DEVD-CHO and z-VAD-FMK were the product of R\&D Technology Int. RPMI 1640 medium and fetal bovine serum were purchased from Invitrogen (Carlsbad, CA, USA). BCA protein assay kit was from PIERCE (Rockford, IL, USA). Anti-cytochrome $c$, Fas, Fas ligand, BiP and CHOP antibodies were from Santa Cruz Biotechnology, Inc. (CA, USA). NOK-1 was the product of Pharmingen (San Diego, CA, USA). Anti-COX IV antibody was from Molecular Probes (Eugene, OR, USA).

\subsection{Cell culture}

The human promyelocytic leukemia cell line HL-60 was obtained from the ATCC (Rockville, MD) and maintained in complete RPMI 1640 medium containing $10 \%(\mathrm{v} / \mathrm{v})$ heat-shocked fetal serum with $100 \mu \mathrm{g} / \mathrm{ml}$ penicillin and $100 \mu \mathrm{g} / \mathrm{ml}$ streptomycin. The culture was incubated at $37^{\circ} \mathrm{C}$ in humidified $5 \%$ $\mathrm{CO}_{2} / 95 \%$ air.

\subsection{Hoechst 33258 staining}

Cells were washed with PBS and fixed in 1\% glutaraldehyde in PBS for 30 min., washed again with PBS and stained with $1 \mathrm{mM}$ Hoechst 33258 for $30 \mathrm{~min}$. The photomicrographs were taken with Leica DM/LM microscope under UV illumination $(380 \mathrm{~nm})$.

\subsection{Flow cytometric analysis of cell apoptosis}

At different time points, treated cells and controls were washed, adjusted to $1 \times 10^{6} \mathrm{ml}$ in fixation. After washing, the $200 \times \mathrm{g}$ centrifuged cell pellets were resuspended in $1 \mathrm{ml}$ of hypotonic fluorochrome solution [propidium iodide (PI) $50 \mu \mathrm{g} / \mathrm{ml}$ in $0.1 \mathrm{M}$ sodium citrate plus $0.1 \%$ Triton X-100; Sigma (MO, USA)]. The samples were placed overnight in the dark at $4{ }^{\circ} \mathrm{C}$, and the PI fluorescence of individual nuclei measured using a FACScan flow cytometer as described [21]. According to the DNA content, an apoptotic ratio was calculated after analysis with Modfit software (DNA Modeling System). The experimental values represented the median from three experiments.

\subsection{DNA fragmentation assay}

DNA fragmentation was isolated as described previously [22] with minor modifications. After treatment, $1 \times 10^{7}$ cells were harvested by pipetting and rinsed with ice-cold TBS. The cell pellets were resuspended in $200 \mu 1$ of lysis buffer (10 mM Tris- $\mathrm{HCl}, \mathrm{pH} 7.4,10 \mathrm{mM}$ EDTA and 1.0\% Triton X-100), incubated for $10 \mathrm{sec}$ at room temperature, and centrifuged at $5000 \times \mathrm{g}$ for $5 \mathrm{~min}$. The supernatants obtained were supplemented with $2 \mu$ of RNase A $(20 \mathrm{mg} / \mathrm{ml})$ at $37{ }^{\circ} \mathrm{C}$ for $2 \mathrm{~h}$ and then with proteinase $\mathrm{K}(200 \mu \mathrm{g} / \mathrm{ml})$ in the presence of $0.5 \%$ SDS for an additional $3 \mathrm{~h}$ at $50{ }^{\circ} \mathrm{C}$. The DNA was extracted, precipitated and analyzed by electrophoresis on $1.8 \%$ agarose gel.

\subsection{Western blotting analysis}

$1 \times 10^{6}$ cells were washed twice with cold PBS and lysed in extraction buffer (25 mM Tris- $\mathrm{HCl}$, $\mathrm{pH} 7.5,20 \mathrm{mM} \mathrm{MgCl}_{2}$, and $150 \mathrm{mM} \mathrm{NaCl}, 1 \%$ Triton X-100, $25 \mu \mathrm{g} / \mathrm{ml}$ leupeptin, and $25 \mu \mathrm{g} / \mathrm{ml}$ aprotinin) for $30 \mathrm{~min}$ on ice. The lysates were centrifuged at $12,000 \times \mathrm{g}$ for $15 \mathrm{~min}$, the supernatants collected and protein concentration determined by BCA protein assay (PIERCE, Rockford, IL, USA). Proteins were separated by $15 \%$ SDS-polyacrylamide gel electrophoresis $(50 \mu \mathrm{g} /$ lane) and electroblotted onto nitrocellulose membrane by standard procedures. Transferred blots were incubated sequentially with blocking agent $(5 \%$ non-fat milk in TBS-Tween), rabbit anti-caspase 3 antibody and horseradish peroxidaseconjugated secondary antibody. Blots were developed by the enhanced chemiluminescence on Hyperfilm according to the manufacturer's instructions.

\subsection{Caspase-3 and caspase-4 activity assay}

Cell lysates were prepared by incubating $2 \times 10^{6}$ cells $/ \mathrm{ml}$ in extraction buffer (25 mM Tris- $\mathrm{HCl}$, pH 7.5, $20 \mathrm{mM} \mathrm{MgCl}$, and $150 \mathrm{mM} \mathrm{NaCl}, 1 \%$ Triton $\mathrm{X}-100,25 \mu \mathrm{g} / \mathrm{ml}$ leupeptin, and $25 \mu \mathrm{g} / \mathrm{ml}$ aprotinin) for $30 \mathrm{~min}$ on ice. Lysates were centrifuged at $12,000 \times \mathrm{g}$ for $15 \mathrm{~min}$, the supernatants collected and protein concentration determined by BCA protein assay (PIERCE, Rockford, IL, USA). Cellular extracts $(30 \mu \mathrm{g})$ were then incubated in a 96-well microtitre plate with 20 ng Ac-DEVD-pNA (caspase-3 activity) or Ac-LEVD-pNA (caspase-4 activity) (Beyotime, Haimen, Jiangsu, PRC) for $2 \mathrm{~h}$ at $37^{\circ} \mathrm{C}$. Caspase activity was measured by cleavage of the Ac-DEVD-pNA or Ac-LEVD-pNA substrate to pNA [15], the absorbance of which was measured at $405 \mathrm{~nm}$. Relative caspase activity was calculated as a ratio of emission of treated cells to untreated cells.

\subsection{Mitochondrial membrane potential assay}

3,3-Dihexyloxacarbocyanine iodide (DiOC6(3)), is a widely used lipophilic cationic cyanine dye to determine mitochondrial membrane potential $[23,24]$. Cells were treated with TCS for different time periods and then incubated with DiOC6(3) $(40 \mathrm{nM})$ for $30 \mathrm{~min}$ at $37^{\circ} \mathrm{C}$. Cells were collected by centrifugation at $3000 \mathrm{rpm}$ for $10 \mathrm{~min}$ and resuspended in $500 \mu \mathrm{l}$ of PBS. Fluorescence intensities of DiOC6(3) were analyzed on a flow cytometer (FACScan, Becton Dickinson) with excitation and emission settings of 484 and $500 \mathrm{~nm}$, respectively. 


\subsection{Preparation of cytosolic and mitochondrial fractions}

After treatment, cells $\left(1 \times 10^{7}\right)$ were collected by centrifugation at $600 \times g$ for 5 min at $4{ }^{\circ} \mathrm{C}$, washed twice with ice-cold PBS and then resuspended in ice-cold transport buffer (20 mM HEPES-KOH, pH 7.3, $110 \mathrm{mM} \mathrm{KAc,} 5 \mathrm{mM} \mathrm{NaAc}$, $2 \mathrm{mM} \mathrm{MgAc}_{2}, 1 \mathrm{mM}$ EGTA) containing $200 \mu \mathrm{g} / \mathrm{ml}$ digitonin for $10 \mathrm{~min}$ on ice. The lysates were then subjected to centrifugation at $700 \times g$ for $10 \mathrm{~min}$ at $4{ }^{\circ} \mathrm{C}$ and the supernatants were centrifuged at $10,000 \mathrm{~g}$ for $15 \mathrm{~min}$ at $4{ }^{\circ} \mathrm{C}$. The supernatants were collected as cytosolic fractions and the pellets were mitochondria-containing fractions [25].

\subsection{Statistical analysis of data}

Data are presented as the mean \pm SEM for the indicated number of separate experiments. Statistical analysis of data was performed with one-way analysis of variance (ANOVA) followed by a $t$-test and $P$-values less than 0.05 as considered significant.

\section{Results}

\subsection{TCS induced HL-60 cells apoptosis in a time- and} dose-dependent manner

We first determined whether TCS induces apoptosis in HL-60 cells by comparing nuclear staining with Hoechst 33258. As clearly shown in Fig. 1A, control cells without treatment demonstrated normal nuclear morphology, while after $24 \mathrm{~h}$ treatment of $100 \mu \mathrm{g} / \mathrm{ml} \mathrm{TCS}$, significant nuclear condensation and morphology changes such as membrane blebbing and apoptotic body formation characteristic of apoptosis were seen. The kinetics of TCS-induced apoptosis of HL-60 cells was further investigated by FACS analysis of the appearance and accumulation of hypodiploid DNA, a characteristic feature of apoptosis. As shown in Fig. 1B, the hypodiploid peak began to appear after treatment with $5 \mu \mathrm{g} / \mathrm{ml}$ TCS for $12 \mathrm{~h}$ and increased with TCS concentration and treatment duration. For further confirmation, the cells were treated with either $100 \mu \mathrm{g} / \mathrm{ml} \mathrm{TCS}$ for $3 \mathrm{~h}, 6 \mathrm{~h}, 12 \mathrm{~h}$, and $24 \mathrm{~h}$ or various concentrations of TCS for $24 \mathrm{~h}$, and DNA fragmentation was investigated. Compared to the vehicle only cells, TCS treatment led to the appearance of DNA ladder in a time- and dose-dependent manner (Fig. 1C). Together, these data indicated that TCS induced apoptosis in HL-60 cells.

\subsection{Involvement of various caspases in TCS-induced HL-60 apoptosis}

To investigate the involvement of various caspase pathways during TCS-induced apoptosis, western blot analysis of TCS-

A
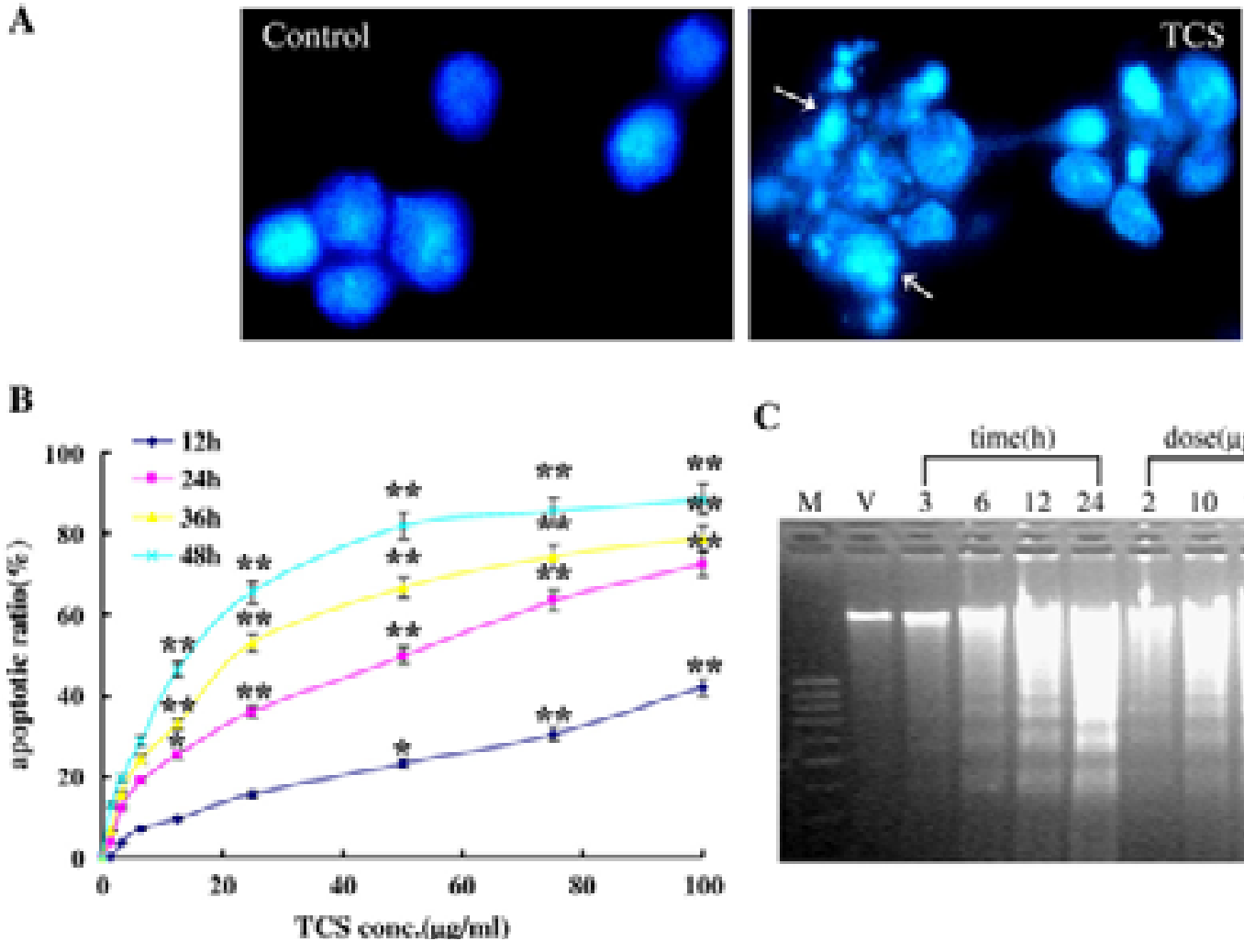

C

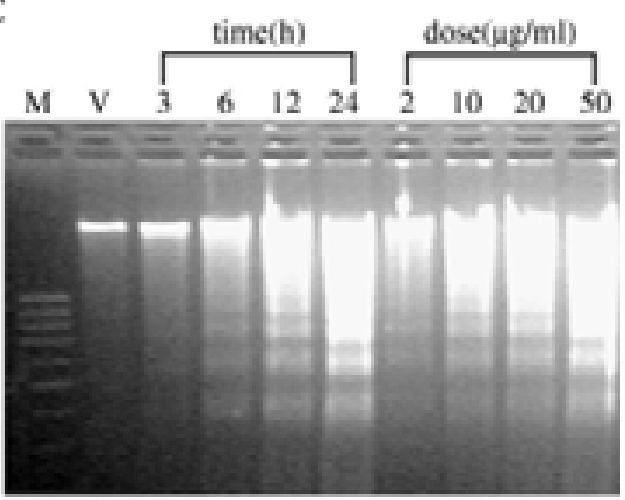

TCS cones $(\mathrm{mg} / \mathrm{ml})$

Fig. 1. TCS induced apoptosis in HL-60 cells in a time- and concentration-dependent manner. (A) After being incubated with (right panel) or without (left panel) $100 \mu \mathrm{g} / \mathrm{ml}$ TCS for $24 \mathrm{~h}$, cells were stained with Hoechst 33258 and images obtained. Many cells demonstrated chromatin condensation, nuclei fragmentation and apoptotic body formation after TCS-treatment (arrows). The results were representative of three independent experiments. (B) HL-60 cells were treated with a range of concentrations $(0-100 \mu \mathrm{g} / \mathrm{ml})$ of TCS over different time periods $(12-48 \mathrm{~h})$ and cell apoptosis was determined by flow cytometry. The percentage of apoptotic cells was calculated as a ratio of sub-G0/G1 (i.e., the hypodiploid peak) in total cells. Values were shown as mean \pm S.E.M. of three independent experiments performed in triplicate. ${ }^{*} P<0.05, * * P<0.01$, compared with untreated cells. (C) The cells were treated with TCS at $100 \mu \mathrm{g} / \mathrm{ml}$ for 3,6 , 12, $24 \mathrm{~h}$, respectively, or at various concentrations for $24 \mathrm{~h}$, the cellular DNA was extracted, dialyzed and separated on a 1.8\% agarose gel and visualized under UV light by ethidium bromide staining. The results were representative of three independent experiments with similar results. M: marker, V: vehicle-treated sample. 
treated cells with the specific antibodies against caspase- $3,-8$ and -9 was performed. The cells were treated with $100 \mu \mathrm{g} / \mathrm{ml}$ TCS for different periods of time or with different concentrations of TCS for $24 \mathrm{~h}$, after which protein extracts were prepared and fractionated by SDS-PAGE. As shown in Fig. 2A, TCS treatment induced the cleavage of the caspase- $8,-9$ and -3 in a dose- and time-dependent manner. Actually, the initiator caspases (i.e., caspase- 9 and -8) were activated within $3 \mathrm{~h}$ treatment of $100 \mu \mathrm{g} / \mathrm{ml} \mathrm{TCS}$, while significant amount of active caspase-3 only occurred after $6 \mathrm{~h}$ treatment (Fig. 2A), consistent with a temporal sequence of events. We then investigated the effect of inhibitors of these caspases on TCS-induced apoptosis. HL-60 cells were pretreated for $2 \mathrm{~h}$ with $100 \mu \mathrm{M}$ z-VAD-FMK, a general caspase inhibitor, and DEVD-CHO, a caspase-3 inhibitor, respectively, followed with $100 \mu \mathrm{g} / \mathrm{ml}$ TCS for additional $24 \mathrm{~h}$, after which the cells were collected and stained with Hoechst 33258. As shown in Fig. 2B, nuclear condensation induced by TCS was almost completely blocked by z-VADFMK or DEVD-CHO pretreatment. The almost complete inhibitory effects of these two caspase inhibitors were also confirmed with quantified data obtained through FACS analysis. As shown in Fig. 2C, the apoptosis was significantly decreased from $73.4 \%$ to $6.23 \%$ by DEVD-CHO or $3.85 \%$ by zVAD-FMK suggesting that caspase- 3 is the common effector caspase of TCS-induced apoptosis. Interestingly, pretreatment of z-IETD-FMK, a caspase 8 inhibitor or z-LEHD-FMK, a caspase 9 inhibitor, significantly inhibited TCS-induced apoptosis to $55.23 \%$ and $41.4 \%$, respectively. Collectively these two inhibitors further significantly reduced apoptosis to $28.2 \%$, suggesting some synergistic effect. However, it is of importance to note that this ratio was still significantly higher than that of caspase 3 inhibitor or general caspase inhibitor $(P<0.05)$, which implicated that there may be other pathway(s) involved in caspase 3 cleavage/activation and apoptosis.

\subsection{ER stress was involved in the apoptosis}

Another important pathway which can trigger the caspase cascade leading to caspase-3 activation and apoptosis is initiated by ER stress $[17,26]$. To study if TCS induces ER stress, we first analyzed the expression levels of GRP78/BiP, induction of which serves as a general response to ER stress. Western blot analysis revealed that GRP78/BiP was significantly upregulated as early as $1 \mathrm{~h}$ following treatment with TCS and remained upregulated until $24 \mathrm{~h}$ (Fig. 3A). Furthermore, we also analyzed expression levels of CHOP/GADD153, which has been implicated in mediating apoptosis during ER stress. As shown in Fig. 3A, CHOP/GADD153 is also increased upon TCS-treatment.

It is known that caspase- 4 acts as the initiator caspase in ER stress-induced apoptosis pathway in human system [17]. Therefore, to further verify that TCS induces apoptosis via the ER stress pathway, we determined whether caspase-4 was involved in TCS-induced HL-60 apoptosis. Cells were treated with $100 \mu \mathrm{g} / \mathrm{ml}$ TCS for various periods of time and cleavage/ activation of caspase-4 was examined by western blot analysis. As shown in Fig. 3B, TCS treatment induced cleavage of caspase- 4 and the active fragments increased in a time and dose-dependent manner. Consistent with western blot analysis, the measurement of caspase-4 specific activity confirmed that caspase- 4 activity was also induced by TCStreatment in a time- and dose-dependent manner (Fig. 3C). To confirm whether caspase-4 activation actually contributes to TCS-induced apoptosis, we determined the effect of z-YVADFMK, a specific caspase-4 inhibitor, on apoptotic ratio assessed by FACS analysis. Indeed, z-YVAD-FMK significantly decreased TCS-induced apoptosis from $72.9 \%$ to $49.5 \%$ (Fig. 3D), suggesting that caspase- 4 partially contributes to TCS-induced apoptosis in HL-60 cells. As expected, cotreatment of z-YVAD-FMK and z-LEHD-FMK, a caspase-9 inhibitor, further dramatically decreased TCS-induced apoptosis to $19.6 \%$ (Fig. 3D), suggesting that these two pathways work in concert to activate caspase-3 and trigger final cell demise. Together, the induction of key ER stress response proteins and activation of caspase-4 strongly support the notion that ER stress is involved in TCS-induced apoptosis in HL-60 cells.

\subsection{Mitochondria were involved in the TCS-induced apoptosis}

Caspase-9 is considered the initiator caspase involved in mitochondria-initiated intrinsic pathway, however, it may also be activated by other signals. Therefore, to confirm the involvement of mitochondria signaling pathway during TCSinduced apoptosis, given that a reduction of mitochondria membrane potential (MMP) is among the early changes in apoptosis, we further investigated the changes in MMP. Cells treated with $100 \mu \mathrm{g} / \mathrm{ml}$ TCS for various periods of time were collected and stained with DiOC6(3), a mitochondrial specific and voltage-dependent dye. Lower levels of DiOC6(3) fluorescence intensity suggested impaired MMP. As shown in Fig. 4A, the percentage of cells with impaired MMP began to increase as early as $1.5 \mathrm{~h}$ after treatment with $100 \mu \mathrm{g} / \mathrm{ml}$ TCS and kept increasing along with increased treatment duration. We also examined the release of critical mitochondrial proteins such as cytochrome $c$ or Smac from the mitochondria to cytosol, a prerequisite step for caspase-9 activation in mitochondriainitiated apoptosis pathway. As shown in Fig. 4B, the absence of COX IV in the cytosolic fraction demonstrated that this fraction was free of mitochondrial contamination. Indeed, the levels of cytochrome $c$ and Smac in cytosolic fractions were also significantly increased by TCS treatment in a timedependent manner, along with a concurrent decrease in mitochondrial cytochrome $c$, confirming the involvement of mitochondria in TCS-induced apoptosis.

\subsection{Fas/FasL signaling pathway was not involved in the apoptosis}

Caspase- 8 was considered as the initiator caspase of death receptor-triggered extrinsic pathway and the activation of caspase- 8 appears to suggest that the extrinsic pathway may play a role in TCS-induced apoptosis. Since Fas receptor system has been extensively studied as a model of death- 
A
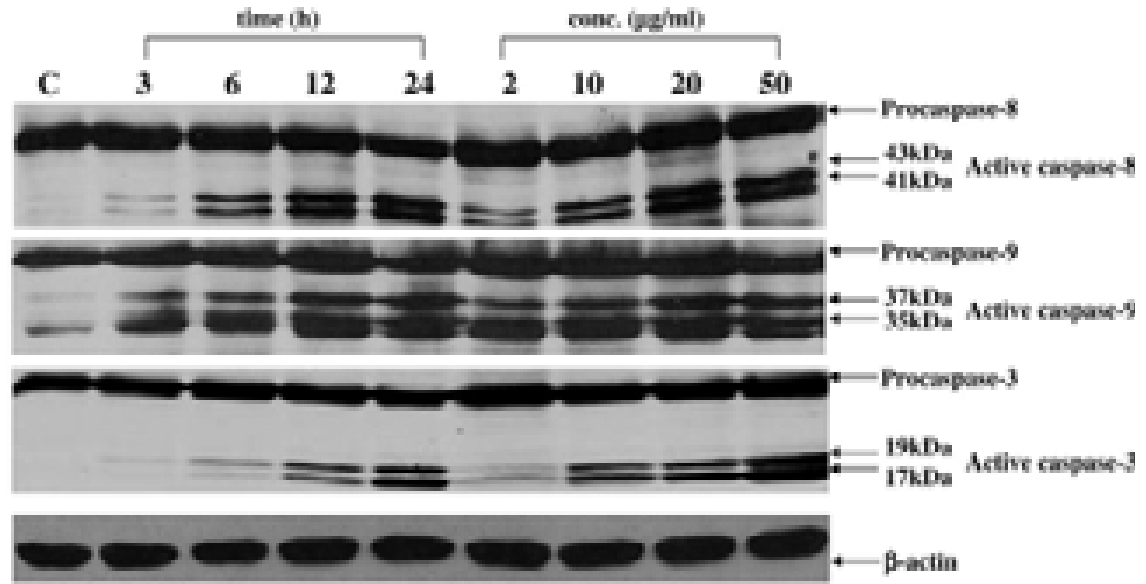

B
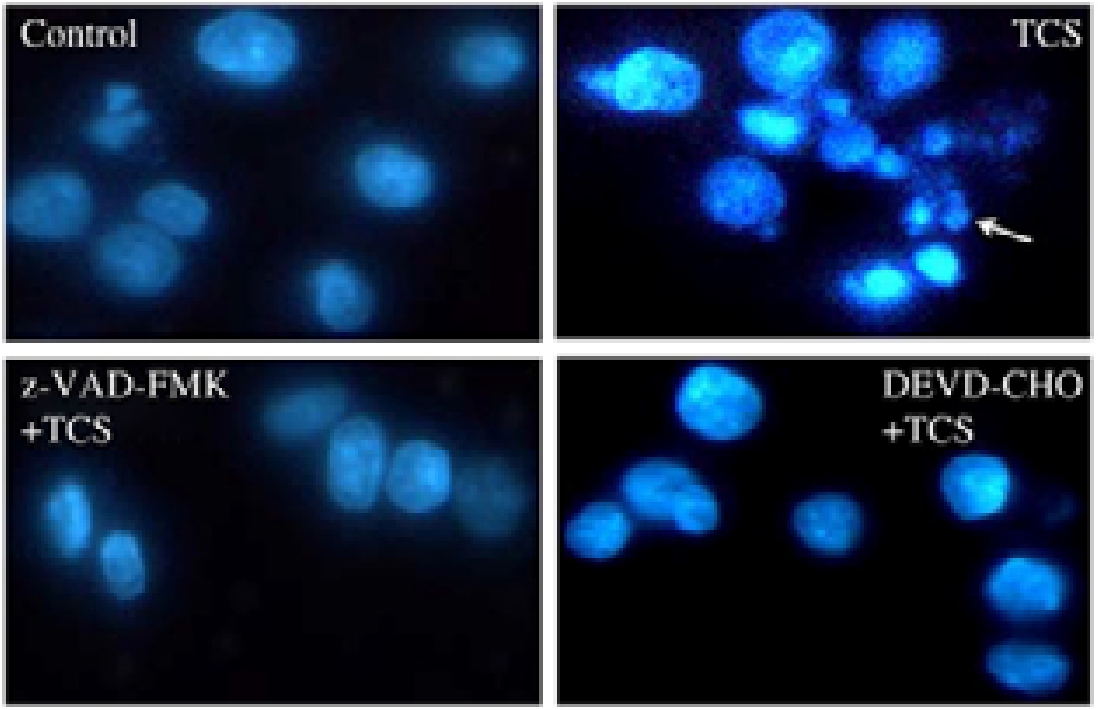

$\mathrm{C}$

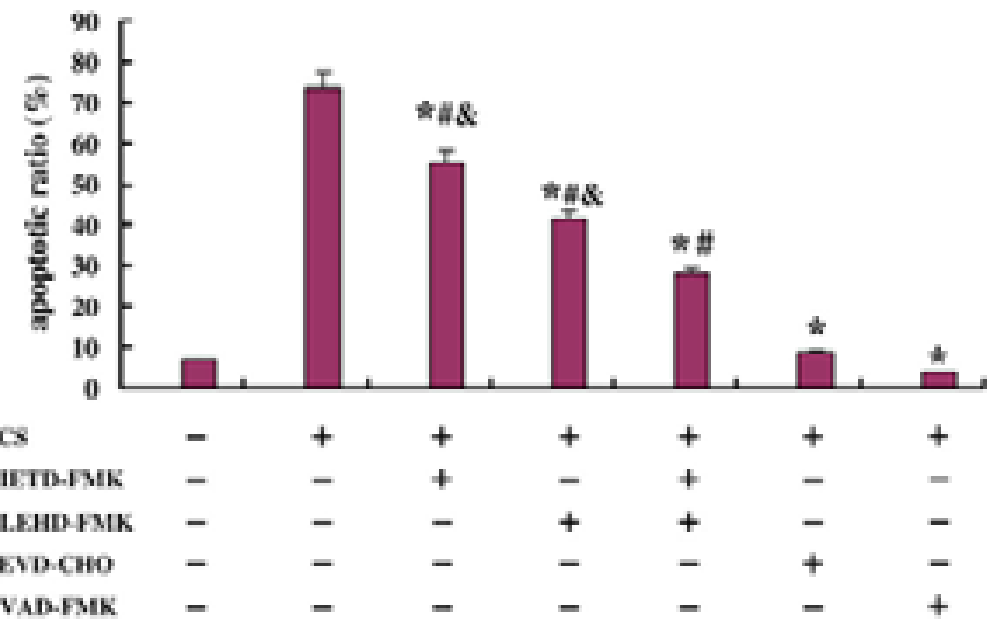

Fig. 2. TCS-induced apoptosis was caspase-dependent. (A) Cells were treated with TCS at $100 \mu \mathrm{g} / \mathrm{ml}$ for 3, 6, 12, $24 \mathrm{~h}$, respectively, or at various concentrations for $24 \mathrm{~h}$. The cleavages of caspase- $8,-9$, and -3 were investigated by immunoblot with appropriate antibodies. $\beta$-actin was probed as a loading control. The experiments were repeated three times with similar results. (B) After pretreatment with $100 \mu \mathrm{M} \mathrm{z}$-VAD-FMK or DEVD-CHO for $2 \mathrm{~h}$ followed by $100 \mu \mathrm{g} / \mathrm{ml}$ TCS treatment for $24 \mathrm{~h}$, cells were stained with Hoechst 33258 and images obtained. Arrow indicated apoptotic nuclear fragmentation. The results were representative of three independent experiments. (C) The effect of caspase inhibitors on TCS-induced apoptosis examined by flow cytometry. Cells were pretreated with $100 \mu \mathrm{M}$ of various caspase inhibitor(s) as indicated for $2 \mathrm{~h}$ followed by an additional $24 \mathrm{~h}$ treatment with $100 \mu \mathrm{g} / \mathrm{ml}$ TCS. The percentage of apoptotic cells was determined by flow cytometry. Results are means \pm S.E.M. of three independent experiments. ${ }^{*} P<0.05$, compared with TCS-treated group; ${ }^{\#} P<0.05$, compared with $z$-VAD-FMK or DEVD-CHO pretreated group; and ${ }^{\&} P<0.05$, compared with z-IETD-FMK + z-LEHD-FMK pretreated group; there was no significant difference between $z$-VADFMK or DEVD-CHO pretreated group. 
A

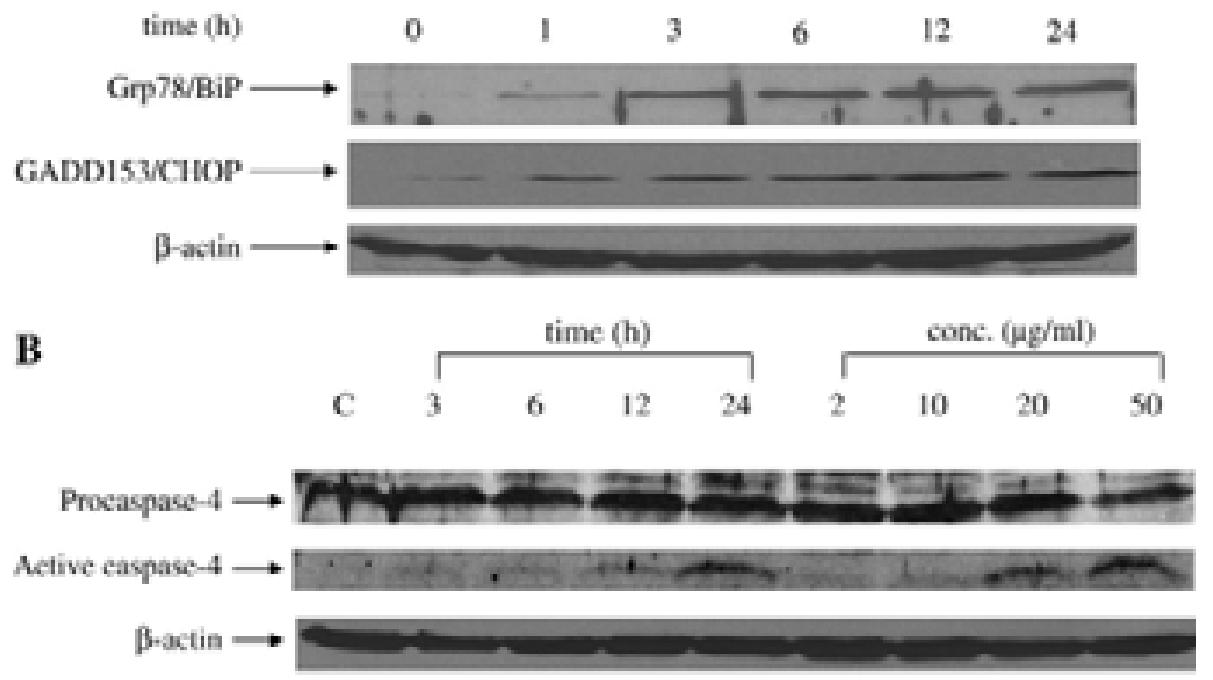

C

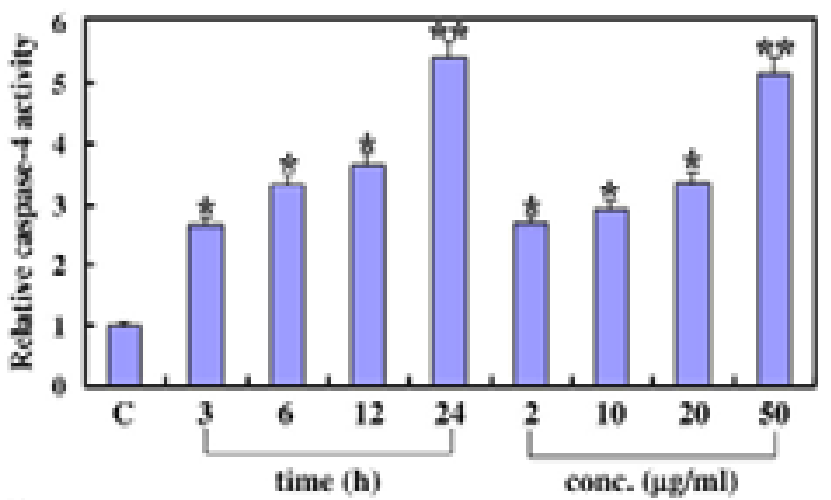

D

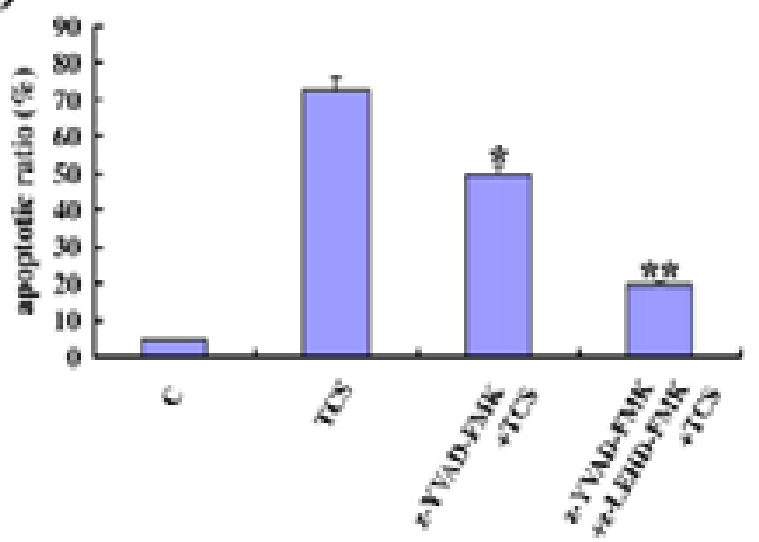

Fig. 3. ER stress was involved in TCS-induced apoptosis. (A) TCS induced upregulation of BiP and CHOP. Cells were treated with $100 \mu \mathrm{g} / \mathrm{ml} \mathrm{TCS} \mathrm{for} 1 \mathrm{~h}, 2 \mathrm{~h}, 3 \mathrm{~h}, 6 \mathrm{~h}$, $12 \mathrm{~h}$ and $24 \mathrm{~h}$, and the expressions of ER stress proteins were analyzed by western blot. $\beta$-actin was used as a loading control. The results were representative of three independent experiments. (B) TCS induced activation of caspase-4. Cells were treated with TCS at $100 \mu \mathrm{g} / \mathrm{ml}$ for $0,3,6,12,24 \mathrm{~h}$, respectively, or at various concentrations for $24 \mathrm{~h}$. The cleavages of caspase- 4 were investigated by western blot with its specific antibody. Because the antibody was more reactive with the proenzyme than with the cleaved fragment, we chose to show the proenzyme after a shorter exposure and the cleaved fragment after a longer exposure of the same membrane. $\beta$-actin was used as a loading control. The experiments were repeated three times with similar results. (C) The effect of TCS on caspase-4 activity in HL-60 cells. Cells were treated as indicated in panel B and the activity of caspase-4 measured using the substrate Ac-LEVD-pNA. Relative caspase-4 activity was calculated as a ratio of emission of treated cells to untreated cells. Results were means \pm S.E.M. of three independent experiments. ${ }^{*} P<0.05$, ${ }^{* *} P<0.01$, compared with control cells. (D) The effect of caspase-4 inhibitor on TCS-induced apoptosis. Cells were pretreated with $100 \mu \mathrm{M} z$-YVAD-FMK or in combination with z-LEHD-FMK, followed with $100 \mu \mathrm{g} / \mathrm{ml} \mathrm{TCS}$ treatment for $24 \mathrm{~h}$, and the apoptosis was determined by FACS analysis. Results were means \pm S.E.M. of three independent experiments. $* P<0.05, * * P<0.01$, compared with TCS-treated group. 

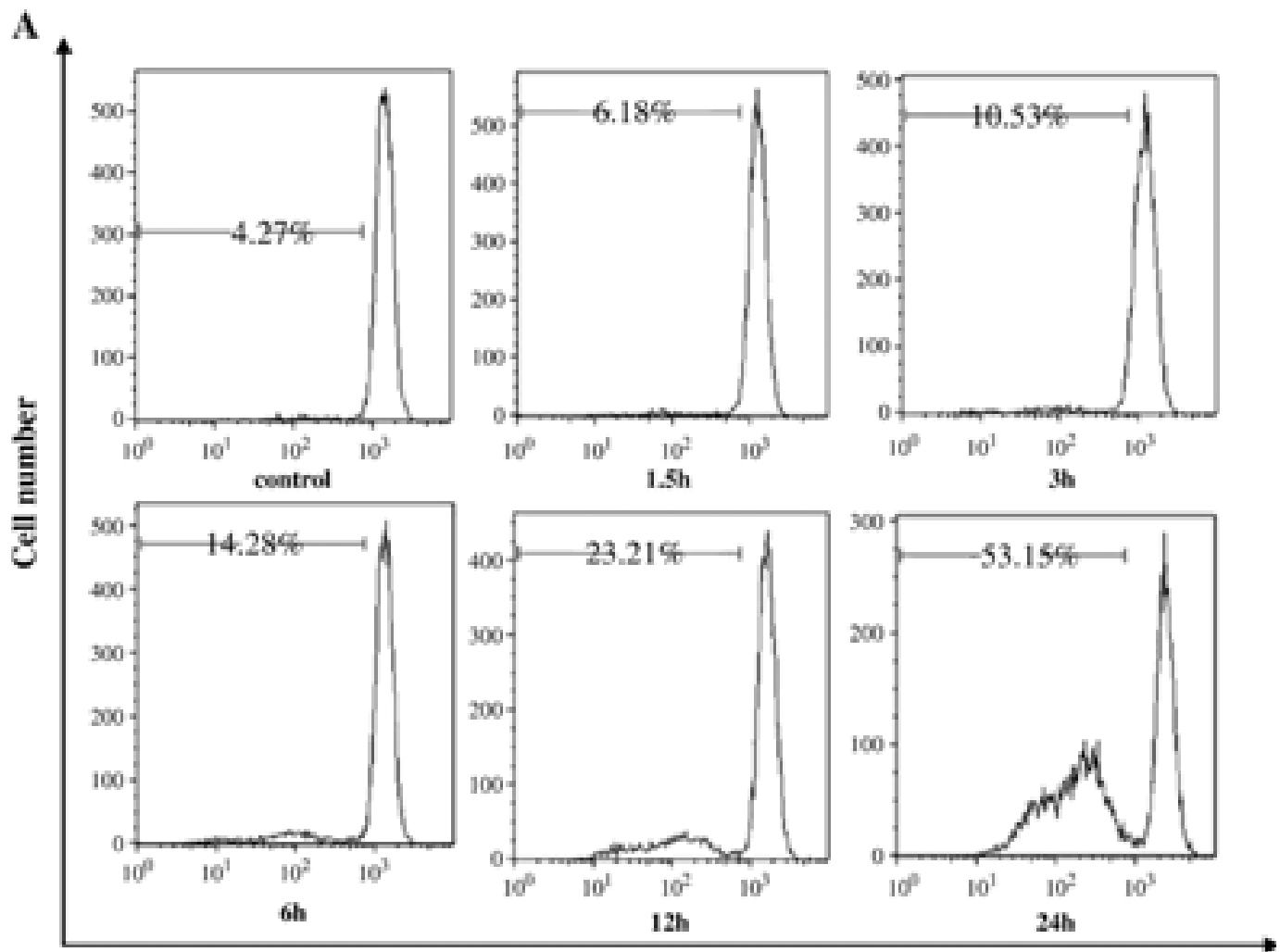

DiOC6(3) intensity

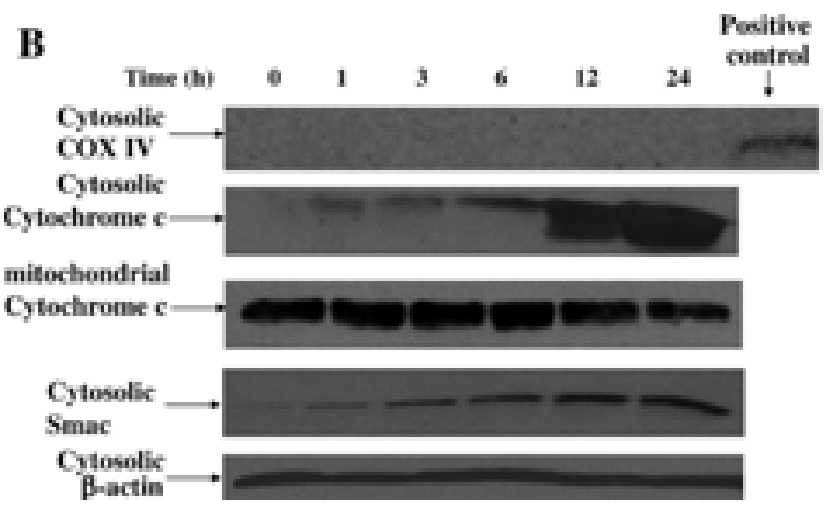

Fig. 4. The mitochondria were involved in TCS-induced apoptosis. (A) TCS treatment disrupted mitochondria membrane potential. HL-60 cells were exposed to $100 \mu \mathrm{g} / \mathrm{ml} \mathrm{TCS}$ for $1 \mathrm{~h}, 3 \mathrm{~h}, 6 \mathrm{~h}, 12 \mathrm{~h}$ and $24 \mathrm{~h}$ respectively, and mitochondrial membrane potential was assessed with DiOC6(3) fluorescence by flow cytometry. One representative experiment out of three independent experiments is shown. (B) TCS induced release of cytochrome $c$ and Smac from mitochondria to cytoplasm. HL-60 cells were exposed to $100 \mu \mathrm{g} / \mathrm{ml}$ TCS for $1 \mathrm{~h}, 3 \mathrm{~h}, 6 \mathrm{~h} 12 \mathrm{~h}$ or $24 \mathrm{~h}$, after which cytosolic and mitochondrial fractions were prepared as described in Materials and methods. The levels of cytochrome $c$ and Smac in these fractions were examined with western blot. The same cytosolic fraction was also probed with COX IV, a mitochondrial membrane protein, to demonstrate that the cytosolic fraction was free of mitochondrial contamination. Mitochondrial fraction was used as a positive control for COX IV. In a parallel gel of cytosolic fraction, $\beta$-actin was used as a loading control. The experiments were repeated three times with similar results.

receptor triggered apoptosis, to investigate the involvement of the extrinsic pathway, Fas and Fas ligand expression were examined by immunoblot analysis. Astonishingly, the expression levels of neither Fas receptor nor Fas ligand were changed by TCS treatment within the 24-h treatment period (Fig. 5A). Furthermore, pre-treatment with Fas-blocking NOK-1 monoclonal antibody $(0.5 \mu \mathrm{g} / \mathrm{ml})$ for $2 \mathrm{~h}$ failed to block TCS-induced apoptosis (Fig. 5B). Collectively, these data excluded the involvement of Fas/FasL pathway in TCSinduced caspase- 8 activation and apoptosis.

\subsection{Caspase-8 was activated via caspase-9 and -4 dependent pathways}

Besides death receptor-triggered apoptotic pathway, caspase8 could be activated by other initiator caspases due to crosstalk between different apoptotic pathways. To explore the activation mechanism of caspase-8, cells were pretreated with $\mathrm{z}$-VADFMK, z-LEHD-FMK or z-YVAD-FMK, respectively before being treated with $100 \mu \mathrm{g} / \mathrm{ml}$ TCS for 24h. As shown in Fig. 6, TCS-induced caspase- 8 cleavage/activation was partially blocked 

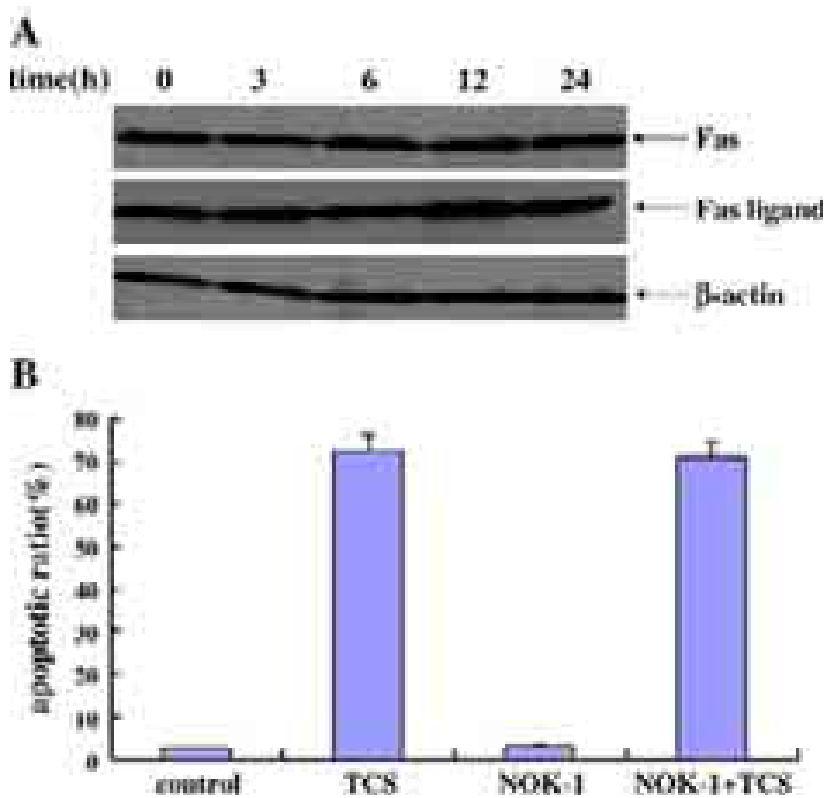

Fig. 5. Fas/Fas ligand signaling pathway was not involved in TCS-induced apoptosis. (A) HL- 60 cells were treated with $100 \mu \mathrm{g} / \mathrm{ml}$ TCS for the indicated periods of time and the expression of Fas and the Fas ligand were examined by western blot analysis using the appropriate antibodies. $\beta$-actin was used as a loading control. The experiments were repeated three times with similar results. (B) Cells were pretreated with $0.5 \mu \mathrm{g} / \mathrm{ml}$ anti-Fas blocking NOK-1 antibodies for $2 \mathrm{~h}$ followed by an additional $24 \mathrm{hr}$ treatment with $100 \mu \mathrm{g} / \mathrm{ml} \mathrm{TCS}$. Apoptosis was examined with flow cytometry. There was no significant difference in NOK-1+TCS treated group compared with TCS-treated alone. Values were shown as mean \pm S.E.M. of three independent experiments.

by $\mathrm{z}$-YVAD-FMK or z-LEHD-FMK pretreatment alone, but almost completely blocked by co-treatment of Z-YVAD-FMK and z-LEHD-FMK. As a positive control, TCS-induced caspase- 8 cleavage/activation was also almost completely inhibited by the pan-caspase inhibitor, z-VAD-FMK pretreatment, as expected. This suggests that both caspase-4 and -9 work upstream of caspase-8.

\subsection{Caspase-8, -9 and -4 acted upstream to the activation of caspase-3}

We demonstrated that caspase-4, -8 and -9 were involved in TCS-induced HL-60 apoptosis. Next, we investigated whether caspase- 3 activation is the common step downstream to each of these initiator caspases by using the specific inhibitors of these caspases. As shown in Fig. 7A, TCS induced production of 17 and $19 \mathrm{kDa}$ active fragments of caspase- 3 which can be partly blocked by the pretreatment with either z-LEHD-FMK, z-YVAD-FMK, or z-IETD-FMK alone. Notably, the production of these active fragments was more dramatically blocked by the treatment of combination of z-LEHD-FMK and z-YVAD-FMK or combination of all three inhibitors which was very similar to the effect of the pan-caspase inhibitor of z-VAD-FMK. In the meantime, we also measured the caspase- 3 specific activity and found that caspase- 3 activity was significantly increased with TCS treatment (Fig. 7B). Consistent with the immunoblot analysis, caspase-3 activity can be partly inhibited by the pretreatment with either z-LEHD-FMK, z-YVAD-FMK, or z-IETD-FMK alone. A more complete inhibition was achieved by the treatment of combination of z-YVAD-FMK and z-LEHD-FMK or combination of all these three inhibitors, which was very similar to the effect of the pan-caspase inhibitor of z-VAD-FMK. Collectively, these data suggested that caspase-3 was activated by each of these pathways.

\section{Discussion}

Many studies reported that TCS induces apoptosis in various tumor cell lines with caspase-3 being involved [1-3]. However, few of them have tried to delineate the specific apoptotic pathways involved. Several upstream pathways may lead to caspase-3 activation and the clarification of their involvement will likely shed new light onto mechanism(s) involved. In the present study, using TCS-induced HL-60 cell death as a model, we thoroughly examined involvement of various apoptotic pathways in TCS-induced apoptosis. We confirmed that caspase-3 plays a major role, and like in other ribosome inactivating proteins-induced apoptosis [27-30], mitochondriadependent intrinsic pathway contributes to TCS-induced caspase-3 activation and apoptosis in HL-60 cells. More importantly, we further demonstrated, for the first time, that ER stress pathway likely also plays an essential role while FasFas ligand-triggered extrinsic pathway appears to not be involved in TCS-induced caspase-3 activation and subsequent apoptosis.

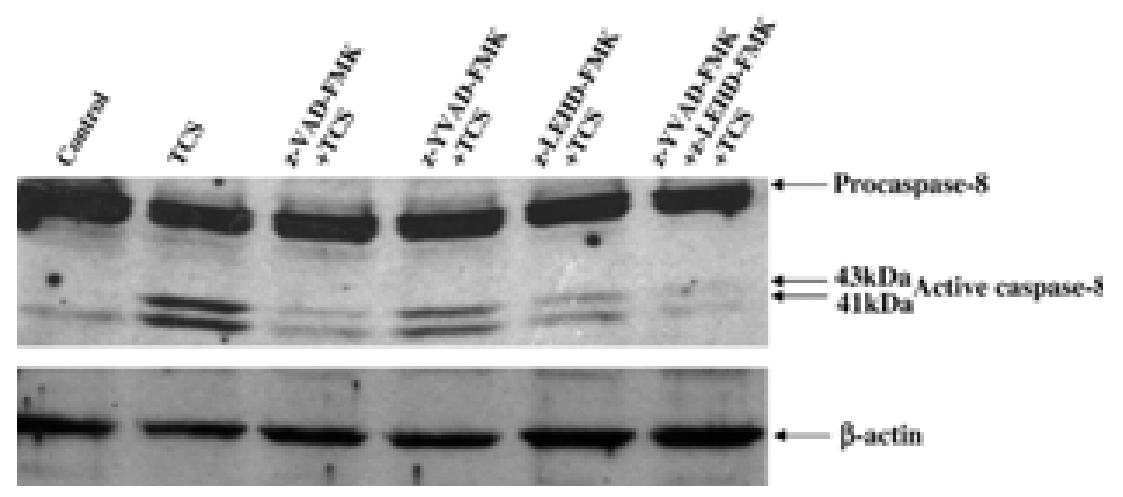

Fig. 6. Caspase-9 and -4 acted upstream to the activation of caspase-8. Cells were pretreated with $100 \mu M$ z-VAD-FMK, z-LEHD-FMK, z-YVAD-FMK or in combination for $2 \mathrm{~h}$ followed by an additional $24 \mathrm{~h}$ treatment of $100 \mu \mathrm{g} / \mathrm{ml}$ TCS. $\beta$-actin was used as a loading control. The results were representative of three independent experiments. 

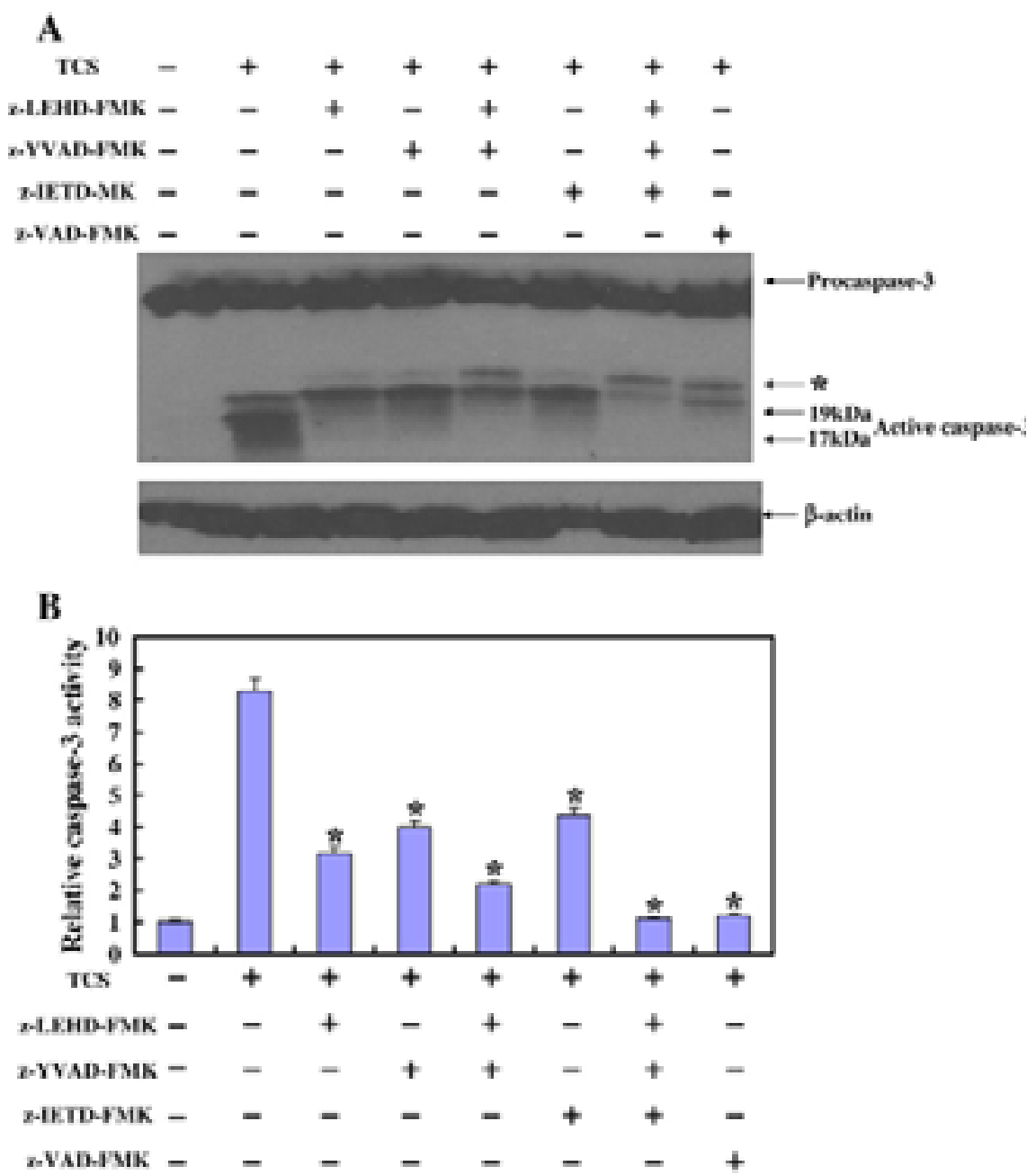

Fig. 7. Caspase-9 and -4 directly activated caspase-3 and indirectly via caspase-8-dependent pathway. (A) Cells were pretreated with z-IETD-FMK, z-LEHD-FMK, $\mathrm{z}$-YVAD-FMK, z-VAD-FMK or in different combinations for $2 \mathrm{~h}$ followed by an additional $24 \mathrm{hr}$ treatment with $100 \mu \mathrm{g} / \mathrm{ml} \mathrm{TCS}$. The activation of caspase-3 was examined by western blot. $\beta$-actin was used as a loading control. The band marked with * was always detected when the cells were pretreated with inhibitors which was likely either a nonspecific band or an inactive intermediate cleavage product. The results were representative of three independent experiments. (B) Cells were treated as indicated in panel A and the activity of caspase-3 was measured using the fluorescence substrate Ac-DEVD-pNA. Relative caspase-3 activity was calculated as a ratio of emission of treated cells to untreated cells. Results were means \pm S.E.M. of three independent experiments. $* P<0.05$, compared with control cells.

Leukemia cell line HL-60 was used in this study and we first confirmed that TCS induced apoptosis in HL-60 cells in a timeand dose-dependent manner with morphological and biochemical evidences such as accumulation of subGo/G1 cells and appearance of DNA ladder (Fig. 1). Interestingly, there was a strong DNA fragmentation and a high activation of caspases at certain conditions when only around $20 \%$ apoptotic cells were detected by flow cytometry (Fig. 1). This probably reflects the different sensitivity of various methods. Indeed, prior studies reported strong changes in biochemical parameters like DNA fragmentation and caspase activity when only a small portion of cells undergo apoptosis [1]. Further investigation indicated that caspases are involved since various caspases were activated and z-VAD-FMK, a general caspase inhibitor, almost completely inhibited TCS-induced apoptosis (Fig. 2). More specifically, DEVD-CHO, a caspase-3 inhibitor, also achieved near complete inhibition (Fig. 2), suggesting that caspase-3 is the major executioner caspase in TCS-induced HL-60 apoptosis. In general, both the mitochondria-initiated intrinsic pathway and the death receptor-triggered extrinsic pathway can lead to caspase- 3 activation. In our system, both caspase- 9 and -8 , the major initiator caspases implicated in these two pathways, were activated and inhibition of either one partially rescued cells from TCS-induced apoptosis (Fig. 2), suggesting that each of these caspases contributed to TCS-induced apoptosis. However, inhibition of both caspases, while leading to further rescue of cells suggestive of some synergistic effect, failed to completely block TCS-induced apoptosis as evidenced by the still significantly higher apoptotic ratio compared to that of caspase-3 inhibitor or pan-caspase inhibitor (Fig. 2C). These data suggested that additional pathway(s) might be involved in TCS-induced apoptosis. Recent studies suggest ER as another subcellular center implicated in apoptotic execution. Many stimuli including alterations in calcium homeostasis, production of reactive oxygen species (ROS) and accumulation of unfolded proteins in the ER can cause ER stress $[9,19]$ and prolonged ER 
stress will ultimately lead to apoptosis. Indeed, TCS induced upregulation of GRP78/BiP, a classical marker for ER stress response, and GADD153/CHOP, another ER stress-induced cell death modulator, in HL-60 cells (Fig. 3) which indicated that TCS induced ER stress. Caspase- 4 is regarded as an initiator caspase in ER stress triggered apoptosis [17]. Our study demonstrated that TCS treatment induced caspase- 4 cleavage and activated caspase- 4 in a time- and dose-dependent manner and that TCS-induced apoptosis was partly blocked by caspase4 inhibitor (Fig. 3B-D), which strongly supported the notion that ER stress signaling pathway is involved in the TCS-induced apoptosis in HL-60 cells. Interestingly, one recent study demonstrated that in ER stress-resistant HL-60 cells, many ribosomal proteins were upregulated and saporin, another RIP, can partially reverse the ER stress-resistant phenotype [31], implicating that RIP may impact ER function and cause or facilitate ER stress which is consistent with our finding. However, it is unclear how TCS may induce ER stress. One potential explanation is that TCS induced elevated $\left[\mathrm{Ca}^{2+}\right]_{i}$ and ROS production like in JAR cells [1] which could cause ER stress. This needs to be tested since we recently found that $\left[\mathrm{Ca}^{2+}\right]_{i}$ and ROS may not be involved in TCS-induced apoptosis in other cell types like K562 [4]. Indeed, in our preliminary study, we also found that calcium appears not to be involved in TCS-induced apoptosis in HL-60 cells either (data not shown). Alternatively, TCS, a type I RIP, could inhibit protein synthesis by inactivating ribosomes in cell-free system by its N-glycosidase activity [32-34]. The inhibitory activity might result in large amounts of immature proteins which would accumulate in the ER as misfolded proteins and cause ER stress.

Another novel finding of our study is that Fas/FasLtriggered extrinsic apoptotic pathway appears not to be involved in TCS-induced apoptosis despite an obvious activation of caspase-8. This is evidenced by a lack of induction of Fas or Fas ligand upon TCS treatment and a lack of inhibitory effect of anti-Fas blocking antibody on TCS-induced apoptosis (Fig. 5). Due to the potential crosstalk among different apoptotic pathways $[20,27]$, we explored the possibility that caspase- 8 is activated by mitochondrial signaling pathway and/or ER stress rather than by Death Inducing Signaling Complex (DISC) during the extrinsic apoptotic pathway. Our study showed that the activation of caspase- 8 was partly blocked by z-LEHDFMK or z-YVAD-FMK pretreatment alone, and almost completely blocked by combination of both inhibitors or z-VAD-FMK (Fig. 6). These data suggested that caspase-8 was activated in a caspase-dependent pathway, and caspase- 9 and -4 acted upstream to the activation of caspase- 8 .

Although the mitochondrion is involved in many RIPinduced apoptosis [27,28], its involvement in TCS-induced apoptosis has not been established. In this study, we first demonstrated that caspase-9 is activated (Fig. 2A, C) which implicated the mitochondrial involvement since caspase- 9 is the initiator caspase for the mitochondria-mediated intrinsic apoptotic pathway. Next, we directly demonstrated that TCS induced impaired mitochondrial membrane potential (Fig. 4A). Moreover, TCS also caused release of key mitochondrial proteins, cytochrome $c$ and Smac, from mitochondria to cytosol (Fig. 4B) which are consistent with caspase-9 activation observed since these are prerequisite steps for caspase-9 activation $[10,11,35,36]$. Given the presence of crosstalk between various apoptotic pathways, one may argue this pathway may be downstream to ER stress-triggered pathway. Our studies using combinations of different caspase inhibitors helped delineate the relationship among them: since neither caspase-4 nor caspase-9 inhibitor alone can completely block caspase- 3 activation and subsequent apoptosis while the combination of caspase- 4 and -9 inhibitors show more dramatic effects, it is likely that TCS induced the activation of these two pathways independently. Collectively our results clearly established the involvement of mitochondria pathway in TCS-induced apoptosis. However, the mechanism regarding how TCS, or more broadly RIP, may induce mitochondrial dysfunction is unclear. One potential cause is that TCS or other RIP might result in the inhibition of synthesis of constitutive protein(s) required to maintain the mitochondrial permeability transition pore (MPTP) in a closed state keeping the apoptotic machinery in check $[28,37]$.

Caspase-3 was implicated in TCS-induced apoptosis in previous studies. We confirmed that actually caspase- 3 may be the only common executioner caspase involved in TCS-induced HL-60 cell apoptosis since DEVD-CHO, the caspase-3 inhibitor, completely blocked TCS-induced apoptosis (Fig. 2). We also demonstrated that both mitochondrial dependent caspase-9 and ER-stress dependent caspase-4 were involved in caspase-3 activation because both z-LEHD-FMK and zYVAD-FMK partly block the cleavage and activity of caspase-3 (Fig. 7A, B). In our immunoblot analysis, a band around $20 \mathrm{kDa}$ was always present whenever a caspase inhibitor was added (Fig. 7A). Because there is no caspase-3 activity detected in many of these conditions (Fig. 7B), this is likely a non-specific band or an inactive intermediate cleavage product, which was also detected in the study of doxorubicin-induced apoptosis by other groups $[38,39]$. Since the inhibition of caspase-8 led to partial inhibition of caspase-3 cleavage and activity and apoptosis (Fig. 7) and caspase- 8 was activated in a caspase- 9

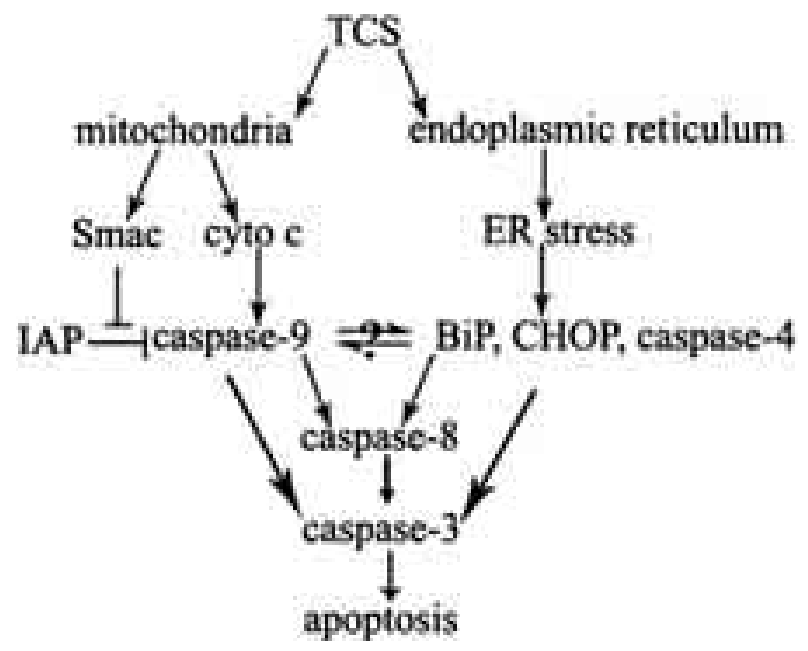

Fig. 8. Proposed scheme of various apoptotic pathways involved in TCSinduced apoptosis in HL-60 cells. 
and -4-dependent manner (Fig. 6), it is likely that caspase-9 and -4 induced caspase- 3 activation both directly and indirectly via caspase-8.

In summary, the present study demonstrated that TCS induced HL-60 cell apoptosis through both the caspase-9dependent mitochondrial pathway and caspase-4-dependent ER stress-triggered pathway. Both initiator caspases directly activated caspase- 3 or via caspase- 8 which eventually leads to apoptosis in HL-60 cells (Fig. 8). Caspase-3 is the major executioner caspase mediating TCS-induced apoptosis.

\section{Acknowledgements}

We thank Dr. Jiacai Wu and Dr. Yihong Hu for thoughtful discussions and critiques of the manuscript. We also thank Xiaoqin Dong for providing access to equipment.

\section{References}

[1] C. Zhang, Y. Gong, H. Ma, C. An, D. Chen, Z.L. Chen, Reactive oxygen species involved in trichosanthin-induced apoptosis of human choriocarcinoma cells, Biochem. J. 355 (2001) 653-661.

[2] C.M. Dou, J.C. Li, Effect of extracts of trichosanthes root tubers on HepAH cells and HeLa cells, World J. Gastroenterol. 10 (2004) 2091-2094.

[3] Y.Y. Wang, D.Y. Ouyang, H. Huang, H. Chan, S.C. Tam, Y.T. Zheng, Enhanced apoptotic action of trichosanthin in HIV-1 infected cells, Biochem. Biophys. Res. Commun. 331 (2005) 1075-1080.

[4] J. Li, X. Xia, H. Nie, M.A. Smith, X. Zhu, PKC inhibition is involved in trichosanthin-induced apoptosis in human chronic myeloid leukemia cell line K562, Biochim. Biophys. Acta 1770 (2007) 63-70.

[5] V. Cryns, J. Yuan, Proteases to die for, Genes Dev. 12 (1998) 1551-1570.

[6] W. Hu, J.J. Kavanagh, Anticancer therapy targeting the apoptotic pathway, Lancet Oncol. 4 (2003) 721-729.

[7] N. Dias, C. Bailly, Drugs targeting mitochondrial functions to control tumor cell growth, Biochem. Pharmacol. 70 (2005) 1-12.

[8] K. Schulze-Osthoff, D. Ferrari, M. Los, S. Wesselborg, M.E. Peter, Apoptosis signaling by death receptors, Eur. J. Biochem. 254 (1998) 439-459.

[9] R.V. Rao, H.M. Ellerby, D.E. Bredesen, Coupling endoplasmic reticulum stress to the cell death program, Cell Death Differ. 11 (2004) 372-380.

[10] I. Budihardjo, H. Oliver, M. Lutter, X. Luo, X. Wang, Biochemical pathways of caspase activation during apoptosis, Annu. Rev. Cell Dev. Biol. 15 (1999) 269-290.

[11] X. Liu, C.N. Kim, J. Yang, R. Jemmerson, X. Wang, Induction of apoptotic program in cell-free extracts: requirement for dATP and cytochrome $c$, Cell 86 (1996) 147-157.

[12] A. Thorburn, Death receptor-induced cell killing, Cell. Signal. 16 (2004) 139-144.

[13] S. Lacour, O. Micheau, A. Hammann, V. Drouineaud, J. Tschopp, E. Solary, M.T. Dimanche-Boitrel, Chemotherapy enhances TNF-related apoptosis-inducing ligand DISC assembly in HT29 human colon cancer cells, Oncogene 22 (2003) 1807-1816.

[14] X. Luo, I. Budihardjo, H. Zou, C. Slaughter, X. Wang, Bid, a Bcl2 interacting protein, mediates cytochrome $c$ release from mitochondria in response to activation of cell surface death receptors, Cell 94 (1998) 481-490.

[15] C.A. Belmokhtar, J. Hillion, E. Segal-Bendirdjian, Staurosporine induces apoptosis through both caspase-dependent and caspase-independent mechanisms, Oncogene 20 (2001) 3354-3362.

[16] J.W. Cheong, S.Y. Chong, J.Y. Kim, J.I. Eom, H.K. Jeung, H.Y. Maeng, S.T. Lee, Y.H. Min, Induction of apoptosis by apicidin, a histone deacetylase inhibitor, via the activation of mitochondria-dependent caspase cascades in human Bcr-Abl-positive leukemia cells, Clin. Cancer Res. 9 (2003) 5018-5027.
[17] J. Hitomi, T. Katayama, Y. Eguchi, T. Kudo, M. Taniguchi, Y. Koyama, T. Manabe, S. Yamagishi, Y. Bando, K. Imaizumi, Y. Tsujimoto, M. Tohyama, Involvement of caspase-4 in endoplasmic reticulum stressinduced apoptosis and Abeta-induced cell death, J. Cell Biol. 165 (2004) $347-356$.

[18] T. Nakagawa, H. Zhu, N. Morishima, E. Li, J. Xu, B.A. Yankner, J. Yuan, Caspase-12 mediates endoplasmic-reticulum-specific apoptosis and cytotoxicity by amyloid-beta, Nature 403 (2000) 98-103.

[19] T. Momoi, Caspases involved in ER stress-mediated cell death, J. Chem. Neuroanat. 28 (2004) 101-105.

[20] A. Jimbo, E. Fujita, Y. Kouroku, J. Ohnishi, N. Inohara, K. Kuida, K. Sakamaki, S. Yonehara, T. Momoi, ER stress induces caspase-8 activation, stimulating cytochrome $c$ release and caspase-9 activation, Exp. Cell Res. 283 (2003) 156-166.

[21] R. Kaul, S. Mukherjee, F. Ahmed, M.K. Bhat, R. Chhipa, S. Galande, S. Chattopadhyay, Direct interaction with and activation of $\mathrm{p} 53$ by SMAR1 retards cell-cycle progression at $\mathrm{G} 2 / \mathrm{M}$ phase and delays tumor growth in mice, Int. J. Cancer 103 (2003) 606-615.

[22] M. Herrmann, H.M. Lorenz, R. Voll, M. Grunke, W. Woith, J.R. Kalden, A rapid and simple method for the isolation of apoptotic DNA fragments, Nucleic Acids Res. 22 (1994) 5506-5507.

[23] U. Ozgen, S. Savasan, S. Buck, Y. Ravindranath, Comparison of DiOC(6) (3) uptake and annexin $\mathrm{V}$ labeling for quantification of apoptosis in leukemia cells and non-malignant $\mathrm{T}$ lymphocytes from children, Cytometry 42 (2000) 74-78.

[24] B.T. Doyle, A.J. O’Neill, J.M. Fitzpatrick, R.W. Watson, Differentiationinduced HL-60 cell apoptosis: a mechanism independent of mitochondrial disruption? Apoptosis 9 (2004) 345-352.

[25] Y. Hu, C. Fang, Y. Xu, The effect of isoforms of the cell polarity protein, human ASIP, on the cell cycle and Fas/FasL-mediated apoptosis in human hepatoma cells, Cell. Mol. Life Sci. 62 (2005) 1974-1983.

[26] R.V. Rao, S. Castro-Obregon, H. Frankowski, M. Schuler, V. Stoka, G. del Rio, D.E. Bredesen, H.M. Ellerby, Coupling endoplasmic reticulum stress to the cell death program. An Apaf-1-independent intrinsic pathway, J. Biol. Chem. 277 (2002) 21836-21842.

[27] H. Bantel, I.H. Engels, W. Voelter, K. Schulze-Osthoff, S. Wesselborg, Mistletoe lectin activates caspase-8/FLICE independently of death receptor signaling and enhances anticancer drug-induced apoptosis, Cancer Res. 59 (1999) 2083-2090.

[28] S. Narayanan, A. Surolia, A.A. Karande, Ribosome-inactivating protein and apoptosis: abrin causes cell death via mitochondrial pathway in Jurkat cells, Biochem. J. 377 (2004) 233-240.

[29] M.S. Kim, J. Lee, K.M. Lee, S.H. Yang, S. Choi, S.Y. Chung, T.Y. Kim, W.H. Jeong, R. Park, Involvement of hydrogen peroxide in mistletoe lectin-II-induced apoptosis of myeloleukemic U937 cells, Life Sci. 73 (2003) 1231-1243.

[30] S.L. Mi, C.C. An, Y. Wang, J.Y. Chen, N.Y. Che, Y. Gao, Z.L. Chen, Trichomislin, a novel ribosome-inactivating protein, induces apoptosis that involves mitochondria and caspase-3, Arch. Biochem. Biophys. 434 (2005) 258-265

[31] Y. Zhang, S.A. Berger, Increased calcium influx and ribosomal content correlate with resistance to endoplasmic reticulum stress-induced cell death in mutant leukemia cell lines, J. Biol. Chem. 279 (2004) 6507-6516.

[32] W.Y. Chan, H. Huang, S.C. Tam, Receptor-mediated endocytosis of trichosanthin in choriocarcinoma cells, Toxicology 186 (2003) 191-203.

[33] W.L. Chan, Y.T. Zheng, H. Huang, S.C. Tam, Relationship between trichosanthin cytotoxicity and its intracellular concentration, Toxicology 177 (2002) 245-251.

[34] S.H. Chan, F.S. Hung, D.S. Chan, P.C. Shaw, Trichosanthin interacts with acidic ribosomal proteins $\mathrm{P} 0$ and $\mathrm{P} 1$ and mitotic checkpoint protein MAD2B, Eur. J. Biochem. 268 (2001) 2107-2112.

[35] D. Chauhan, T. Hideshima, S. Rosen, J.C. Reed, S. Kharbanda, K.C. Anderson, Apaf-1/cytochrome $c$-independent and Smac-dependent induction of apoptosis in multiple myeloma (MM) cells, J. Biol. Chem. 276 (2001) 24453-24456.

[36] V.M. Dirsch, I.M. Muller, S.T. Eichhorst, G.R. Pettit, Y. Kamano, M. Inoue, J.P. Xu, Y. Ichihara, G. Wanner, A.M. Vollmar, Cephalostatin 1 selectively triggers the release of Smac/DIABLO and subsequent apoptosis 
that is characterized by an increased density of the mitochondrial matrix, Cancer Res. 63 (2003) 8869-8876.

[37] B.A. Narayanan, M.S. Condon, M.C. Bosland, N.K. Narayanan, B.S Reddy, Suppression of N-methyl-N-nitrosourea/testosterone-induced rat prostate cancer growth by celecoxib: effects on cyclooxygenase-2, cell cycle regulation, and apoptosis mechanism(s), Clin. Cancer Res. 9 (2003) 3503-3513.
[38] S. Gamen, A. Anel, P. Perez-Galan, P. Lasierra, D. Johnson, A. Pineiro, J. Naval, Doxorubicin treatment activates a Z-VAD-sensitive caspase, which causes deltapsim loss, caspase-9 activity, and apoptosis in Jurkat cells, Exp. Cell Res. 258 (2000) 223-235.

[39] J. Wu, T. Liu, J. Xie, F. Xin, L. Guo, Mitochondria and calpains mediate caspase-dependent apoptosis induced by doxycycline in HeLa cells, Cell. Mol. Life Sci. 63 (2006) 949-957. 